Cite this: J. Mater. Chem. C, 2013, 1, 7222

Received 16th June 2013

Accepted 19th September 2013

DOI: $10.1039 /$ c3tc31161a

www.rsc.org/MaterialsC

\section{Ultra low dielectric, self-cleansing and highly oleophobic POSS-PFCP aryl ether polymer composites}

\author{
Babloo Sharma, $\uparrow^{\mathrm{a}}$ Rajneesh Verma,$\uparrow^{\mathrm{a}}$ Cary Baur, $\dagger^{\mathrm{a}}$ Julia Bykova, $\dagger^{\mathrm{b}}$ Joseph M. Mabry ${ }^{\mathrm{c}}$ \\ and Dennis W. Smith, Jr. ${ }^{* a}$
}

\begin{abstract}
Ultra low dielectric constant $(k=1.53)$ materials with self-cleansing properties were synthesized via incorporation of fluorodecyl-polyhedral oligomeric silsesquioxane (FD-POSS) into recently synthesized perfluorocyclopentenyl (PFCP) aryl ether polymers. Incorporation of fluorine rich, high free volume, and low surface energy POSS into a semifluorinated PFCP polymer matrix at various weight percentages resulted in a dramatic drop in dielectric constant, as well as a significant increase in hydrophobicity and oleophobicity of the system. These ultra-low dielectric self-cleansing materials $\left(\theta_{\text {tilt }}=38^{\circ}\right)$ were fabricated into electrospun mats from a solvent blend of fluorinated FD-POSS with PFCP polymers.
\end{abstract}

\section{Introduction}

Continual efforts to reduce the size of micro-electronics have brought about new obstacles such as signal crosstalk, resistivecapacitance time delays and power dissipation. ${ }^{1}$ These problems are mainly derived from unwanted capacitances due to the close proximity of the circuitry and electronic components. To combat these problems, innovative efforts are constantly being carried out to design and synthesize new, ultra-low dielectric constant $(k \leq 2)$ materials. Such efforts include the incorporation of fluorine, ${ }^{2}$ sol gel based techniques, ${ }^{3}$ and nano-pore formation via thermal degradation. ${ }^{4}$ However, most of these processes have drawbacks such as the requirement of post functionalization, poor thermal and mechanical material properties, and the non-uniform or incomplete removal of the thermally unstable component.

Over the years, electrospinning has emerged as a useful tool to design low $k$, non-woven mats of submicron diameter range fibers with large surface area to volume ratios. ${ }^{5}$ However, recent efforts to produce low $k$ materials using polyamide and polyacrylonitrile via the electrospinning technique have suffered greatly from the problem of moisture absorption. ${ }^{6}$ A small amount of water absorption $(k=80.1)$ significantly increases the overall $k$ value of the materials. Therefore there is a constant search for low $k$ materials that are hydrophobic while possessing thermal and chemical stability.

${ }^{a}$ Department of Chemistry and The Alan G. MacDiarmid NanoTech Institute, The University of Texas at Dallas, Richardson, TX 75083, USA. E-mail: dwsmith@ utdallas.edu; Fax: +1 972883 2915; Tel: +1 9728832782

${ }^{b}$ Department of Physics and The Alan G. MacDiarmid NanoTech Institute, The University of Texas at Dallas, Richardson, TX 75083, USA

${ }^{c}$ Air Force Research Laboratory, Propellants Branch, Edwards Air Force Base, CA 93524, USA

$\dagger$ Authors have equally contributed.
Biological systems around us provide many examples of highly hydrophobic, self-cleansing materials; with the most well-known example being the lotus leaf. This peculiar property arises from micron-sized hierarchical roughness of the leaf surface. $^{7}$ There have been attempts to mimic these features through surface etching/exfolication, ${ }^{8}$ lithography/patterning, ${ }^{9}$ deposition $^{\mathbf{1 0}}$ or self-assembly. ${ }^{\mathbf{1 1}}$ These methods involve severe chemical treatment, elaborate patterning and other time consuming and costly processes. A singular material with no requirement of cost and time intensive fabrication processes would be a significant breakthrough in the field of low $k$ dielectrics and would undoubtedly lead to lower production costs and higher performance in microelectronics.

Polyhedral oligomeric silsesquioxane (POSS) possesses a hybrid inorganic architecture with a silicon-oxygen cubic core framework, functionalized with organic groups at each silicon atom (Fig. 1). POSS has been incorporated in polymer matrices, either as a blend or covalently attached, to modify the basic properties of the system such as glass transition temperature, crystallinity, oleophobicity, hydrophobicity, and dielectric constant ranging from $2-3 .^{12}$

The high thermal stability and chemical resistance of fluorinated polymers leave them better equipped than their

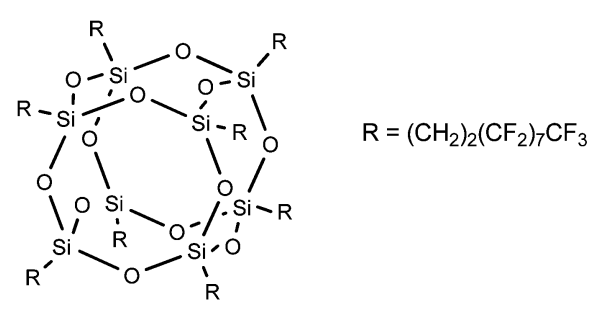

Fig. 1 Fluorodecyl-polyhedral oligomeric silsesquioxane (FD-POSS). 
hydrocarbon counterparts for surface coating applications..$^{13}$ Due to the carbon-fluorine bond along the polymer chain, fluoropolymers inherently possess a high degree of hydrophobicity and inertness to organic based solvents. Therefore, fluoropolymers are good candidates for oil and water repellent applications.

We have recently synthesized a unique class of fluoropolymers, namely, perfluorocyclopentenyl (PFCP) aryl ether polymer from commercially available feedstocks. These polymers are highly thermally stable and show a decomposition temperature, at $5 \%$ weight loss, above $400{ }^{\circ} \mathrm{C}$. Thermal properties such as the glass transition $\left(T_{\mathrm{g}}\right)$ can be altered depending on the spacer group, $R$ (Scheme 1). ${ }^{\mathbf{1 4}}$

In this paper, a new material combining all highly desired properties: ultra-low dielectric constant, superhydrophobicity, and high oleophobicity is fabricated through the introduction of FD-POSS into PFCP aryl ether polymer. In addition to possessing the above properties, high processability and thermal stability is retained in the composite. The incorporation of FD-POSS is reasonable because of its large fluorine content and low dielectric constant. Such materials would be highly desired for a wide variety of commercial applications including microelectronics, paint, glass, and textile industries.

\section{Experimental section}

\section{Materials}

Tetrahydrofuran (THF) was purchased from Alfa Aesar, hexafluorobenzene (HFB) was purchased from Sigma Aldrich and used as received. FD-POSS was donated from the Air Force Research Laboratory Materials Application Branch, Edwards Air Force Base and used without further purification. The perfluorocyclopentenyl-biphenol (PFCP-BP) polymer $\left(M_{\mathrm{n}}=24300\right.$, $M_{\mathrm{w}}=45900$, PDI $=1.8$ ) was synthesized and characterized by following the procedures described in our previous work. ${ }^{\mathbf{1 4 a}}$

\section{Electrospinning}

The co-solvent system for electrospinning consisted of THF and HFB in a 1:1 ratio by volume. FD-POSS concentration was varied while keeping the concentration of PFCP-BP polymer constant $(29 \% \mathrm{w} / \mathrm{v}$ of the solvent mixture). The concentrations

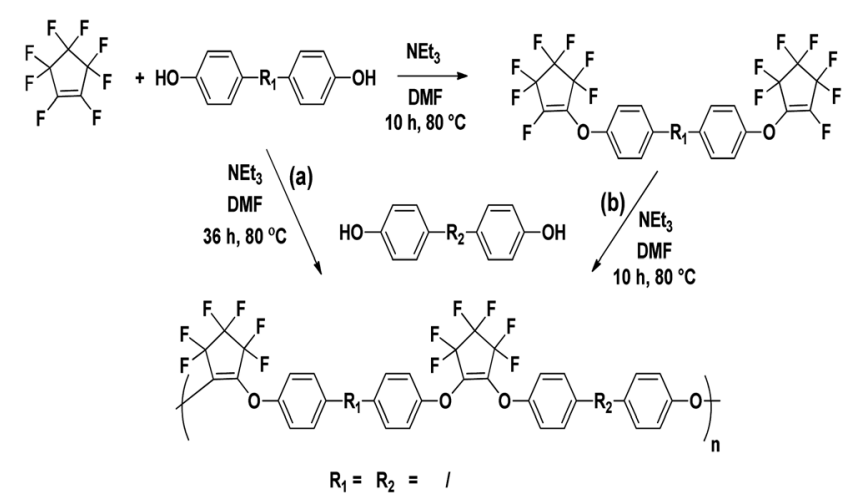

Scheme 1 (a) Synthesis of PFCP aryl ether polymer via commercially available commodities. (b) Synthesis of PFCP aryl ether monomers and polymers therefrom. of the FD-POSS composites were 4, 8, and $15 \mathrm{wt} \%$ of the polymer. The 15\% FD-POSS solution showed POSS precipitation; therefore $0.05 \mathrm{~mL}$ of HFB was added to redissolve the POSS. PFCP-BP/FD-POSS blend solution was filled in a $12 \mathrm{~mL}$ syringe equipped with a metallic needle. The distance between the metallic needle and the collector plate was kept at $9 \mathrm{~cm}$. The inter-electrode voltage was $20 \mathrm{kV}$. The ejection rate of the solution was set to $0.5 \mathrm{~mL} \mathrm{~h}^{-1}$ and the electrospinning was carried out in atmosphere at room temperature. Aluminum foil was used as a substrate to collect the fibers.

\section{Instrumental details}

Dielectric constant measurement was conducted with a Radiant Technologies Precision Premier ferroelectric tester. Electrospun samples were roughly $80 \mu \mathrm{m}$ thick, and were cut into $1 \mathrm{~cm}^{2}$. Film thickness has effect on properties including hydrophobicity, oleophobicity and dielectric constant values. ${ }^{15} \mathrm{We}$ found that the electrospun films of thickness lower than $80 \mu \mathrm{m}$ are too fragile to do the dielectric measurements. A conductive layer of silver was deposited on the upper surface as an electrode, while conductive aluminum foil acted as the lower electrode. $\mathrm{A} \pm 9 \mathrm{~V}$ $\mu \mathrm{m}^{-1}$ electrical field was placed on the samples at an oscillating frequency of $100 \mathrm{~Hz}$. The charge that developed in the sample was plotted versus the applied voltage, and the slope was used to find the dielectric constant. ${ }^{16}$ Samples were measured 3 times each and show a standard deviation of under $5 \%$.

Contact angle measurements to determine the degree of hydrophobicity and oleophobicity of the electrospun mats were carried out on a Rame-Hart goniometer (Model no. 5000115). A drop of 4-5 $\mu \mathrm{L}$ of deionized water or hexadecane was used. Drops were placed on 7-8 different areas of the electrospun mat and an average of 10 values is reported. A standard deviation of $\pm 3^{\circ}$ is observed in the contact angle analysis.

The morphology of the electrospun mats was observed with scanning electron microscopy (Zeiss supra 40 SEM) and high resolution transmission electron microscopy (JEOL 2100FImaging TEM) and the elemental compositions of the electrospun surfaces were determined by EDX Genesis software attached to the SEM. All samples were thinly sputter coated $(V=$ $125 \mathrm{mV}, I=10 \mathrm{~mA}$ and $t=80 \mathrm{~s}$ ) with Pd to a thickness of 4550 Å using a Hummer VI sputter prior to SEM and EDX analysis. The thermal stability and the glass transition were determined by using TGA (Mettler Toledo DSC/TGA 1) and DSC (Mettler Toledo DSC-1) in nitrogenous atmosphere with a heating rate of $10{ }^{\circ} \mathrm{C} \mathrm{h}^{-1}$ from $25-800{ }^{\circ} \mathrm{C}$ and $0-200{ }^{\circ} \mathrm{C}$, respectively. Four representative samples from the electrospun mats were chosen for thermal analysis and the average value for glass transition temperature $\left(T_{\mathrm{g}}\right)$, decomposition temperature $\left(T_{\mathrm{d}}\right)$ and melting temperature $\left(T_{\mathrm{m}}\right)$ is reported. Standard deviations below $\pm 2{ }^{\circ} \mathrm{C}$ were observed.

\section{Results and discussion}

\section{Analysis of dielectric constant}

Fig. 2 shows the change in the dielectric constant $(k)$ upon changing the processing technique. A spin coated, free standing 


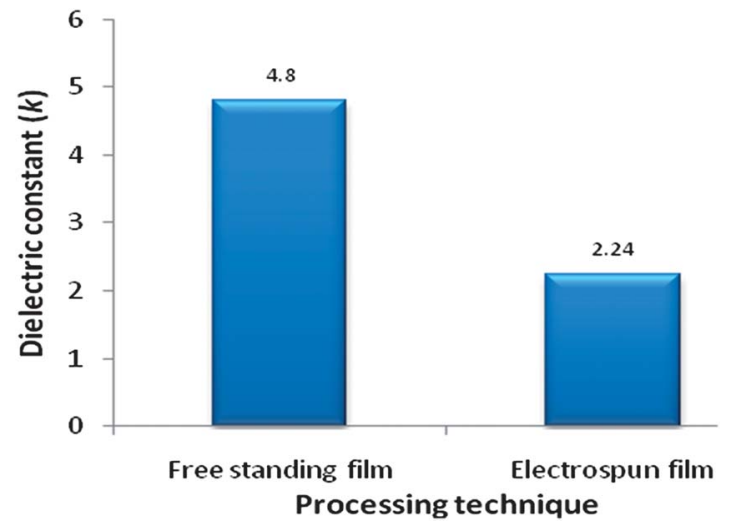

Fig. 2 Effect of processing technique on dielectric constant.

film of PFCP-BP polymer shows a dielectric constant of 4.8 . When the same material is electrospun, the dielectric constant is drastically reduced to 2.24 . The SEM images of these films are shown in Fig. 3.

The electrospun membrane possess countless air pockets/ interstitial sites formed by stacked, beaded, fibrous layers. These interstitial sites naturally allow air penetration $(k=1)$, thereby reducing the overall dielectric constant. ${ }^{17}$ The important effect of reducing the overall dielectric constant of a material by increasing the internal free volume was explored by Lee and Mikoshiba. ${ }^{18}$

Fig. 4 reveals a decrease in the $k$ value with an increase in FD-POSS concentration. The reduction in the dielectric
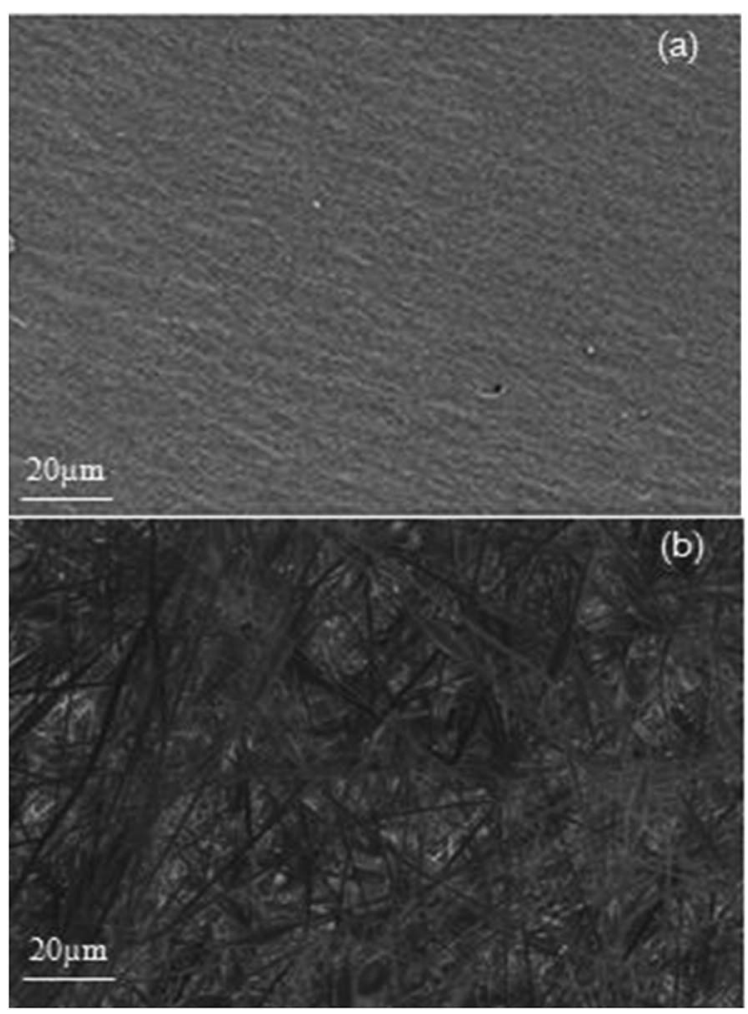

Fig. 3 SEM of (a) PFCP-BP solution cast film (b) electrospun PFCP-BP surface.

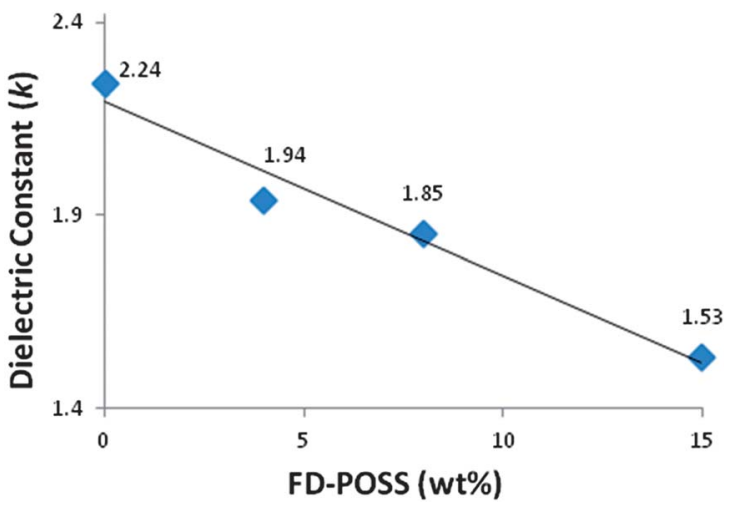

Fig. 4 Effect of increasing the concentration of the FD-POSS on the dielectric constant of the electrospun PFCP-BP/FD-POSS composites.

constant of the PFCP-BP/FD-POSS composites can be explained in terms of the presence of FD-POSS in the PFCP matrix. ${ }^{17} \mathrm{SEM}$ images show the more prominent bead-on-string morphology with an increase in the concentration of FD-POSS in PFCP-BP/ FD-POSS composites (Fig. 5) ${ }^{19}$ which further results in a higher number of air pockets in the electrospun mats; thus lowering the dielectric constant. ${ }^{17,18,20}$

Furthermore, the addition of fluorine atoms with the addition of FD-POSS into the polymer matrix may also decrease the $k$-values due to the low polarizability of the C-F bond. ${ }^{21}$ The surfaces of the beaded fibers of PFCP-BP/FD-POSS composite at 15 wt\% FD-POSS were smooth and showed no nano-scale structures (Fig. 5d).

It has been reported that the large difference in surface energy between POSS and fluoropolymers results in nano-phase separations in composites. ${ }^{12 c}$ To further investigate the nanoscale structures and phase separation, TEM imaging of electrospun mats of PFCP-BP/FD-POSS composites was performed. The TEM images showed that the FD-POSS distribution in PFCP-BP fibers was homogenous for 4 and 8 wt $\%$ FD-POSS

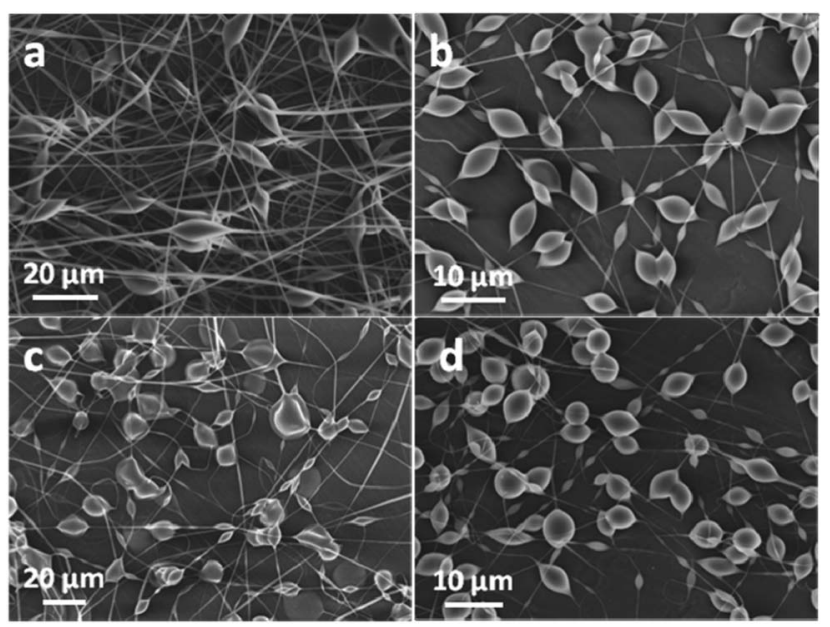

Fig. 5 SEM of film (a) electrospun PFCP-BP surface (b) PFCP-BP $+4 \%$ FD-POSS electrospun surface (c) PFCP-BP + 8\% FD-POSS electrospun surface (d) PFCP-BP + $15 \%$ FD-POSS electrospun surface. 
composites but not for the $15 \mathrm{wt} \%$, (Fig. 6). Agglomerates with an average size of 100-200 $\mathrm{nm}$ were observed in the electrospun mat of PFCP-BP/FD-POSS composite at 15 wt $\%$ FD-POSS (Fig. 6d). ${ }^{12 c, 22}$

\section{Contact angle analysis}

Static contact angle analysis of the electrospun surfaces of the PFCP-BP/FD-POSS composites shows an increase in the contact angle for both water and hexadecane as the concentration of FD-POSS is increased (Fig. 7). The highest contact angle achieved for water is $154^{\circ}$ with a sliding angle of $38^{\circ}$, (Fig. 8). The high sliding angle may be due to the low trapped air ratio at the solid water interface which can gave rise to sliding resistance. ${ }^{23}$ EDX analysis shows that there is an increase in the concentration of fluorine on the surface as the concentration of the FD-POSS is increased (Tables 1 and 2). The slight variation in the theoretical and the experimental EDX analysis of various elements in the electrospun mats might be due to the coating of the samples before EDX analysis. This increase is a contributing factor to the increase in contact angle as evidenced by earlier research. ${ }^{24}$

SEM imaging showed that the electrospun PFCP-BP/FDPOSS (15 wt\%) composite exhibits primarily a bead-on-string morphology, caused by the onset of chain entanglement (Fig. 7). This is an indication of the low resistance of the jet to extensional flow. ${ }^{25}$ Yoon and co-workers showed that beading morphology provided macro-roughness for electrospun fibers of PHBV and facilitated an enhanced hydrophobicity. ${ }^{26}$

\section{Thermal analysis}

To investigate the effect of FD-POSS on the thermal stability and glass transition temperature of the PFCP-BP polymer
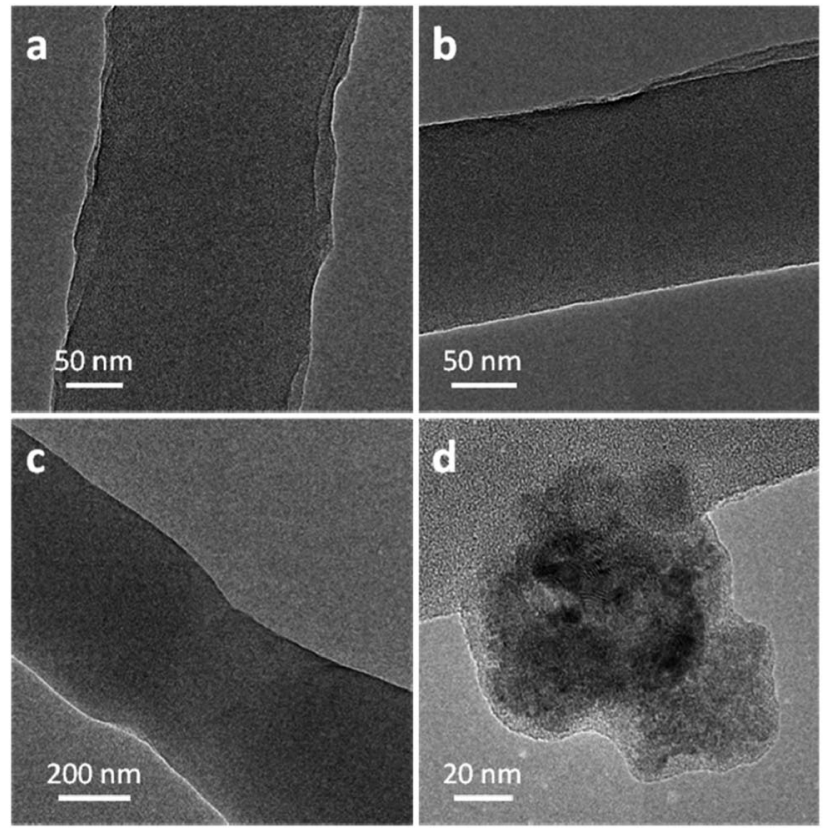

Fig. 6 TEM of (a) PFCP-BP fiber (b) PFCP-BP + 4\% FD-POSS composite fiber (c) PFCP-BP $+8 \%$ FD-POSS composite fiber.

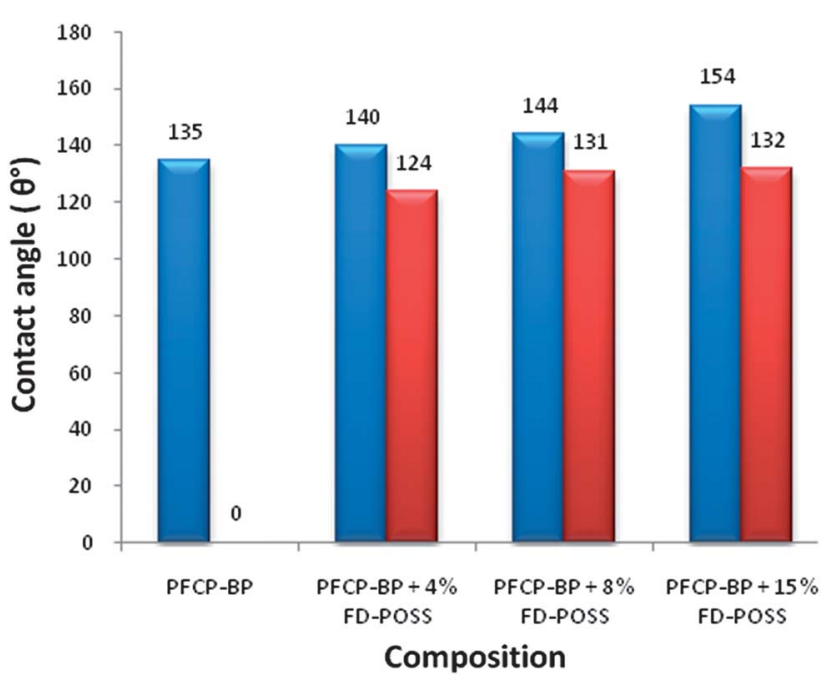

Fig. 7 Effect of FD-POSS on hydrophobicity (blue bar) and oleophobicity (red bar) of electrospun mats.

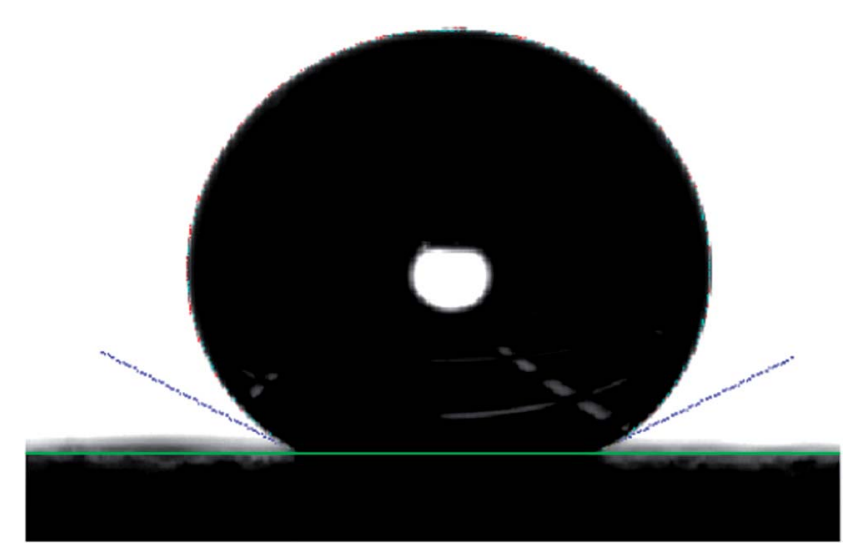

Fig. 8 Super-hydrophobic electrospun surface of PFCP-BP $+15 \%$ FD-POSS composite.

composites, DSC and TGA analysis were performed. Previous studies have shown that POSS-polymer interactions can greatly effect the thermal stability $\left(T_{\mathrm{d}}\right)$ of composites. ${ }^{27}$ Soto and coworkers found that the addition of glycidylethyl-POSS and poly(ethylene glycol)-POSS to polyoxymethylene decreases the $T_{\mathrm{d}}$ of the composites. ${ }^{28}$ Zeng and Tang also observed a decrease in the thermal stability of epoxy polymer nanocomposites and nanopapers with the incorporation of POSS macromers. ${ }^{29,30} \mathrm{We}$

Table 1 EDX analysis of the electrospun PFCP-BP/FD-POSS composites (experimental)

\begin{tabular}{lllll}
\hline & \multicolumn{4}{l}{ EDXs in wt\% } \\
\cline { 2 - 5 } Composition & Carbon & Oxygen & Fluorine & Silicon \\
\hline PFCP-BP & 67.55 & 8.69 & 23.76 & - \\
PFCP-BP + 4\% FD-POSS & 61.88 & 8.51 & 29.10 & 0.51 \\
PFCP-BP + 8\% FD-POSS & 60.45 & 8.61 & 30.17 & 0.76 \\
PFCP-BP + 15\% FD-POSS & 58.41 & 8.65 & 31.60 & 1.33
\end{tabular}


Table 2 EDX analysis of the electrospun PFCP-BP/FD-POSS composites (theoretical)

\begin{tabular}{lllll}
\hline & \multicolumn{4}{l}{ EDXs in wt\% } \\
\cline { 2 - 5 } Composition & Carbon & Oxygen & Fluorine & Silicon \\
\hline PFCP-BP & 58.31 & 9.13 & 32.55 & - \\
PFCP-BP + 4\% FD-POSS & 56.92 & 8.96 & 33.87 & 0.23 \\
PFCP-BP + 8\% FD-POSS & 55.54 & 8.78 & 35.20 & 0.46 \\
PFCP-BP + 15\% FD-POSS & 53.13 & 8.48 & 37.51 & 0.86 \\
\hline
\end{tabular}

Table 3 Thermal characteristics of the neat polymer and the blends

\begin{tabular}{llll}
\hline Composition & $T_{\mathrm{g}}\left({ }^{\circ} \mathrm{C}\right)$ & $T_{\mathrm{d}}{ }^{a}\left({ }^{\circ} \mathrm{C}\right)$ & $T_{\mathrm{m}}\left({ }^{\circ} \mathrm{C}\right)$ \\
\hline FD-POSS & - & 390 & 142 \\
PFCP-BP & 103 & 480 & - \\
PFCP-BP + 4\% FD-POSS & 104 & 425 & - \\
PFCP-BP + 8\% FD-POSS & 102 & 415 & - \\
PFCP-BP + 15\% FD-POSS & 103 & 410 & -
\end{tabular}

${ }^{a}$ Catastrophic degradation temperature in nitrogenous atmosphere.

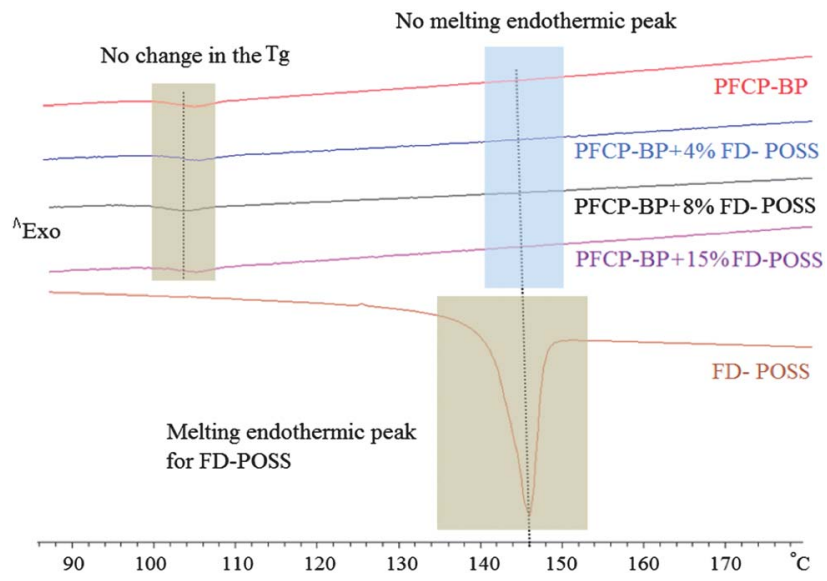

Fig. 9 DSC thermogram of the PFCP-BP, FD-POSS and the electrospun composites.

observed that with an increase in the concentration of FD-POSS in the PFCP-BP matrix the thermal stabilities $\left(T_{\mathrm{d}}\right)$ of the composites decrease. Possible reasons for this reduction in thermal stability include, but are not limited to, back-biting and chain clevage. ${ }^{28-32}$

Pure FD-POSS shows a melting endothermic peak at $142{ }^{\circ} \mathrm{C}$ due to the disruption of crystalinity. ${ }^{12 c}$ No crystalline melting endothermic peaks appeared for the electrospun composites of PFCP-BP/FD-POSS, only glass transition temperatures were observed (Table 3 and Fig. 9). ${ }^{12 c, 33}$ The variation of glass transition temperature in the PFCP-BP/FD-POSS composites is the net result of several effects: free volume fraction, steric barrier, and POSS-polymeric segment interactions. ${ }^{34}$ The glass transitions of the composites were very close to that of the neat PFCPBP polymer, indicating that FD-POSS did not act as a plasticizer (Table 3). The absence of the melting peak suggests that the
FD-POSS remains uncrystallized in the PFCP-BP matrix. ${ }^{12 c, 33}$ Another possibility here is that the crystallization of FD-POSS in PFCP-BP matrix does occur, however, the crystallite sizes are too small, most likely in nanometer size, and at very low overall content. Thus the DSC analysis may not be sensitive enough to show the melting peaks. ${ }^{12 c, 33}$

\section{Conclusions}

We have developed the first ultra low dielectric, highly hydrophobic, oleophobic, and self-cleansing composite of PFCP aryl ether polymers through blending with FD-POSS. The bead on string morphology combined with high surface fluorine content results in a unique combination of highly desirable properties. These composites can be used in microelectronics, paint, and in the textile industry for their unique thermal stability, low dielectric constant, very high hydrophobicity, and oleophobicity.

\section{Acknowledgements}

The authors want to express their gratitude to Intel Corporation (Grant \# 4606175), Welch Foundation (Grant \# AT-0041), NSF-IUCRC Center for Energy Harvesting Materials and Systems (CEHMS) (Grant \# IIP-1035024), US Air Force Office of Scientific Research (contract FA9550-09-1-0384) and The University of Texas at Dallas for their financial support.

\section{Notes and references}

1 (a) S. J. Martin, J. P. Godschalx, M. E. Mills, E. O. Shaffer and P. H. Townsend, Adv. Mater., 2000, 12, 1769-1778; (b) M. Morgen, E. T. Ryan, J.-H. Zhao, C. Hu, T. Cho and P. S. Ho, Annu. Rev. Mater. Sci., 2000, 30, 645.

2 (a) D.-J. Liaw and W.-T. Tseng, Macromol. Symp., 2003, 199, 351-362; (b) M. G. Dhara and S. Banerjee, Prog. Polym. Sci., 2010, 35, 1022-1077.

3 (a) K. Su, D. R. Bujalski, K. Eguchi, G. V. Gordon, D.-L. Ou, P. Chevalier, S. Hu and R. P. Boisvert, Chem. Mater., 2005, 17, 2520-2529; (b) S. Yang, P. A. Mirau, C.-S. Pai, O. Nalamasu, E. Reichmanis, J. C. Pai, Y. S. Obeng, J. Seputro, E. K. Lin, H.-J. Lee, J. Sun and D. W. Gidley, Chem. Mater., 2002, 14, 369-374.

4 (a) W. C. Wang, R. H. Vora, E. T. Kang, K. G. Neoh, C. K. Ong and L. F. Chen, Adv. Mater., 2004, 16, 54-57; (b) L. Jiang, J. Liu, D. Wu, H. Li and R. Jin, Thin Solid Films, 2006, 510, 241-246; (c) Y. W. Chen, W. C. Wang, W. H. Yu, E. T. Kang, K. G. Neoh, R. H. Vora, C. K. Ong and L. F. Chen, J. Mater. Chem., 2004, 14, 1406-1412.

5 A. Greiner and J. H. Wendorff, Angew. Chem., Int. Ed., 2007, 46, 5670-5703.

6 (a) J. Liu, Y. Min, J. Chen, H. Zhou and C. Wang, Macromol. Rapid Commun., 2007, 28, 215-219; (b) L. Yongxin, L. Xiaofeng, L. Xincai, Z. Chengcheng, L. Xiang, Z. Wanjin and W. Ce, Appl. Phys. A: Mater. Sci. Process., 2010, 100, 207-212.

7 (a) T. Sun, L. Feng, X. Gao and L. Jiang, Acc. Chem. Res., 2005, 38, 644-652; (b) W. Barthlott and C. Neinhuis, Planta, 1997, 
202, 1-8; (c) G. D. Bixler and B. Bhushan, Philos. Trans. $R$. Soc., A, 2012, 370, 2381-2417; (d) B. Bhushan, Y. C. Jung and K. Koch, Philos. Trans. R. Soc., A, 2009, 367, 1631-1672.

8 (a) A. Ruiz, A. Valsesia, G. Ceccone, D. Gilliland, P. Colpo and F. Rossi, Langmuir, 2007, 23, 12984-12989; (b) J. J. Lin, C. C. Chu, M. L. Chiang and W. C. Tsai, Adv. Mater., 2006, 18, 3248-3252.

9 (a) D. Öner and T. J. McCarthy, Langmuir, 2000, 16, 77777782; (b) E. Puukilainen, T. Rasilainen, M. Suvanto and T. A. Pakkanen, Langmuir, 2007, 23, 7263-7268.

10 (a) L. Zhu, Y. Xiu, J. Xu, P. A. Tamirisa, D. W. Hess and C.-P. Wong, Langmuir, 2005, 21, 11208-11212; (b) H. F. Hoefnagels, D. Wu, G. de With and W. Ming, Langmuir, 2007, 23, 13158-13163; (c) K. K. S. Lau, J. Bico, K. B. K. Teo, M. Chhowalla, G. A. J. Amaratunga, W. I. Milne, G. H. McKinley and K. K. Gleason, Nano Lett., 2003, 3, 1701-1705; (d) L. Zhai, F. Ç. Cebeci, R. E. Cohen and M. F. Rubner, Nano Lett., 2004, 4, 1349-1353.

11 (a) G. Zhang, D. Wang, Z.-Z. Gu and H. Möhwald, Langmuir, 2005, 21, 9143-9148; (b) J. A. Howarter and J. P. Youngblood, Adv. Mater., 2007, 19, 3838-3843.

12 (a) S. T. Iacono, S. M. Budy, J. M. Mabry and D. W. Smith, Macromolecules, 2007, 40, 9517-9522; (b) G. Li, L. Wang, H. Ni and C. Pittman, Jr, J. Inorg. Organomet. Polym., 2001, 11, 123-154; (c) S. T. Iacono, S. M. Budy, D. W. Smith and J. M. Mabry, J. Mater. Chem., 2010, 20, 2979-2984; (d) C.-M. Leu, Y.-T. Chang and K.-H. Wei, Chem. Mater., 2003, 15, 3721-3727; (e) C.-M. Leu, G. M. Reddy, K.-H. Wei and C.-F. Shu, Chem. Mater., 2003, 15, 2261-2265; (f) Y.-J. Lee, J.-M. Huang, S.-W. Kuo, J.-S. Lu and F.-C. Chang, Polymer, 2005, 46, 173-181; $(g)$ Y.-J. Lee, J.-M. Huang, S.-W. Kuo and F.-C. Chang, Polymer, 2005, 46, 10056-10065.

13 (a) B. Ameduri, Well-Architectured Fluoropolymers: Synthesis, Properties and Applications, Elsevier Science, San Diego, 2004; (b) J. Scheirs, Modern Fluoropolymers: High Performance Polymers for Diverse Applications, Wiley, New York, 1997; (c) S. T. Iacono, S. M. Budy, J. Jin and D. W. Smith Jr, J. Polym. Sci., Part A: Polym. Chem., 2007, 45, 5705-5721.

14 (a) J. M. Cracowski, B. Sharma, D. K. Brown, K. Christensen, B. R. Lund and D. W. Smith, Macromolecules, 2012, 45, 766771; (b) B. Sharma, D. G. VanDerveer, S. M. Liff and D. W. Smith, Tetrahedron Lett., 2013, 54, 3609-3612.

15 (a) J. M. F. Jabal, L. McGarry, A. Sobczyk and D. E. Aston, Langmuir, 2010, 26, 13550-13555; (b) C. Basceri, S. K. Streiffer, A. I. Kingon and R. Waser, J. Appl. Phys., 1997, 82, 2497; (c) G. W. Dietz, M. Schumacher, R. Waser, S. K. Streiffer, C. Basceri and A. I. Kingon, J. Appl. Phys., 1997, 82, 2359-2364; (d) H. K. Kim and F. G. Shi, IEEE Trans. Dielectr. Electr. Insul., 2001, 8, 248-252.

16 C. Baur, J. R. DiMaio, E. McAllister, R. Hossini, E. Wagener, J. Ballato, S. Priya, A. Ballato and J. D. W. Smith, J. Appl. Phys., 2012, 112, 124104-124107.

17 R. M. A. Azzam, Ellipsometry and polarized light, Elsevier, Amsterdam, 1977.
18 (a) B. Lee, Y.-H. Park, Y.-T. Hwang, W. Oh, J. Yoon and M. Ree, Nat. Mater., 2005, 4, 147-150; (b) S. Mikoshiba and S. Hayase, J. Mater. Chem., 1999, 9, 591-598.

19 (a) E. S. Cozza, O. Monticelli and E. Marsano, Macromol. Mater. Eng., 2010, 295, 791-795; (b) K. Kim, Y. Seo, B. Kim, K. Yoon, M. Khil, H. Kim and I. Kim, Colloid Polym. Sci., 2011, 289, 863-870.

20 (a) A. Qu, X. Wen, P. Pi, J. Cheng and Z. Yang, J. Mater. Sci. Technol., 2008, 24, 693-699; (b) S. Srinivasan, S. S. Chhatre, J. M. Mabry, R. E. Cohen and G. H. McKinley, Polymer, 2011, 52, 3209-3218.

21 (a) T. Matsuura, M. Ishizawa, Y. Hasuda and S. Nishi, Macromolecules, 1992, 25, 3540-3545; (b) A. C. Misra, G. Tesoro, G. Hougham and S. M. Pendharkar, Polymer, 1992, 33, 1078-1082; (c) S. Ando, T. Matsuura and S. Nishi, Polymer, 1992, 33, 2934-2939.

22 (a) S. T. Iacono, S. M. Budy, J. M. Mabry and D. W. Smith Jr, Polymer, 2007, 48, 4637-4645; (b) D. Kuo, C. Chang, T. Su, W. Wang and B. Lin, Mater. Chem. Phys., 2004, 85, 201206; (c) J. Xu and C. P. Wong, Composites, Part A, 2007, 38, 13-19; (d) T. Jesionowski and A. Krysztafkiewicz, Appl. Surf. Sci., 2001, 172, 18-32.

23 M. Miwa, A. Nakajima, A. Fujishima, K. Hashimoto and T. Watanabe, Langmuir, 2000, 16, 5754-5760.

24 (a) R. Verma, S. Creager, J. Ballato and D. W. Smith, Polym. Int., 2013, 62, 1152-1158; (b) R. Verma, N. Tomar, S. E. Creager and D. W. Smith Jr, Polymer, 2012, 53, 2211-2216; (c) A. Singh, L. Steely and H. R. Allcock, Langmuir, 2005, 21, 11604-11607; (d) V. A. Ganesh, A. S. Nair, H. K. Raut, T. T. Yuan Tan, C. He, S. Ramakrishna and J. Xu, J. Mater. Chem., 2012, 22, 18479-18485; (e) A. Meskini, M. Raihane and B. Ameduri, Macromolecules, 2009, 42, 3532-3539.

25 (a) J. Tao and S. Shivkumar, Mater. Lett., 2007, 61, 23252328; (b) P. Gupta, C. Elkins, T. E. Long and G. L. Wilkes, Polymer, 2005, 46, 4799-4810; (c) J. D. Ferry, Viscoelastic properties of polymers, Wiley, New York, 1980.

26 Y. I. Yoon, H. S. Moon, W. S. Lyoo, T. S. Lee and W. H. Park, J. Colloid Interface Sci., 2008, 320, 91-95.

27 E. Ayandele, B. Sarkar and P. Alexandridis, Nanomaterials, 2012, 2, 445-475.

28 M. Sánchez-Soto, S. Illescas, H. Milliman, D. A. Schiraldi and A. Arostegui, Macromol. Mater. Eng., 2010, 295, 846-858.

29 K. Zeng and S. Zheng, J. Phys. Chem. B, 2007, 111, 13919-13928. 30 Y. Tang, J. Zhuge, J. Gou, R. Chen, C. Ibeh and Y. Hu, Polym. Adv. Technol., 2011, 22, 1403-1413.

31 Y. R. Liu, Y. D. Huang and L. Liu, Polym. Degrad. Stab., 2006, 91, 2731-2738.

32 (a) L. Song, Q. He, Y. Hu, H. Chen and L. Liu, Polym. Degrad. Stab., 2008, 93, 627-639; (b) M. Sánchez-Soto, D. A. Schiraldi and S. Illescas, Eur. Polym. J., 2009, 45, 341-352.

33 (a) E. S. Cozza, Q. Ma, O. Monticelli and P. Cebe, Eur. Polym. J., 2013, 49, 33-40; (b) Y. Zhao and D. A. Schiraldi, Polymer, 2005, 46, 11640-11647.

34 J. Wu, T. S. Haddad and P. T. Mather, Macromolecules, 2009, 42, 1142-1152. 